\title{
Construction and Prospect of Water Distribution Network Information System in Central Areas of Shanghai
}

\author{
Shihu Shu ${ }^{1, *}$, Minqun Meng ${ }^{2}$, Lijian Zhang ${ }^{2}$ and Xinyue Liu ${ }^{1}$ \\ ${ }^{1}$ National Engineering Research for Urban Water Resource, Shanghai 200082, China \\ ${ }^{2}$ Shanghai Water Supply Dispatching and Monitoring Center, Shanghai 200100, China \\ ${ }^{*}$ Corresponding author
}

\begin{abstract}
The overview of water distribution network information system in central areas of Shanghai was described in this paper. Existing problems were analyzed and further applications of hydraulic model and water quality model to the water distribution network were discussed as well. The development and application of water quality model should be strengthened. It was recommended that each part of the information system should be maintained, updated in a timely manner in order to construct an integrated water distribution network information system.
\end{abstract}

Keywords-water distribution network; digital water quality; information platform; model application; system integration

\section{INTRODUCTION}

With the rapid development of Shanghai's economy, the urban water supply industry has become the fundamental industry for the development of urban economy and social progress. The construction and management of urban water supply facilities has been developing rapidly, and the water supply quantity has steadily increased, and the scale of water distribution network has been expanding. As a result, improving the scientific and technological level of water supply field has addressed substantial attention from the leadership. At present, Shanghai Municipal Water Supply Controlling and Monitoring Center is strengthening its management, and has gained improvements especially in water supply information management, computer application technology development, etc. Information systems such as supervisory control and data acquisition (SCADA), geographic information system (GIS), and hydraulic models for pipe network have been established and applied successfully, which has laid a solid foundation for achieving the goal of "digital water" in Shanghai.

\section{OVERVIEW OF WATER SUPPLY IN CENTRAL AREA OF SHANGHAI}

Water in central Shanghai is supply by four water companies (City South, City North, Pudong Veolia, and Minhang Water Company). Multiple pipes are set by the four companies connecting their sub-network, forming an interconnected water supply network. The central area of Shanghai has a total of 17 water plants (2 raw water plants, 15 water plants), and 51 booster pump stations. The maximum daily water supply of Shanghai exceeds $1000 \times 10^{4} \mathrm{~m}^{3}$, serving more than 20 million people. The maximum daily water supply in 2009 is about $670 \times 10^{4} \mathrm{~m}^{3}$, and the maximum daily water supply in 2010 is $700 \times 10^{4} \mathrm{~m}^{3}$. The length of pipes larger than DN500 (including DN500) is about $2887 \mathrm{~km}$, which is one of the largest water distribution networks in China.

The operation data of secondary pump stations and booster pump stations from four water companies are sent to Shanghai Municipal Water Supply Controlling and Monitoring Center. They are responsible for monitoring the pipe pressure changes, and inform the water dispatch center of detecting unusual signals. Operators will then change the pump status according to the outlet pressure requirements in order to meet the pressure needs of users. Combined with the historical dispatching experience, Shanghai Municipal Water Supply Controlling and Monitoring Center has provided reference values for the followings: pressure control range, starting scheme, instant flow rate of plant outlet, water level of clear water tanks and the pressure of control point in pipe networks.

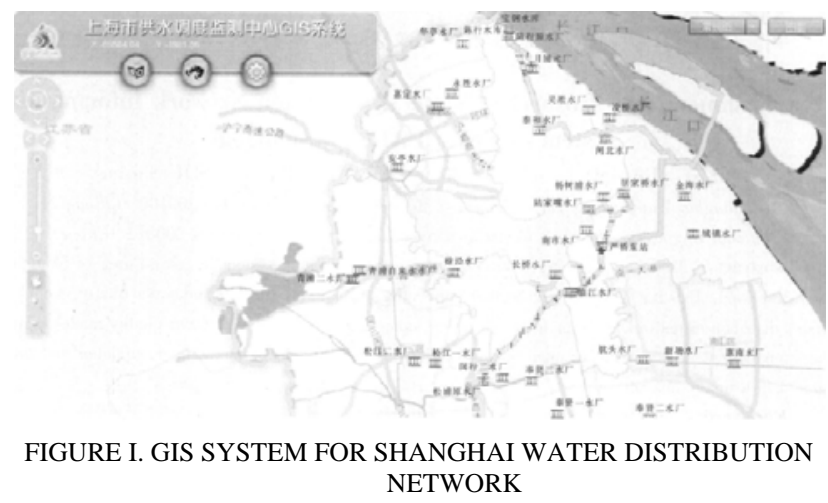

\section{GIS FOR WATER DiSTRIBUTION NETWORK}

GIS for Shanghai water distribution network collected the graphic information of pipes larger than DN500 from four water companies (City South, City North, Pudong Veolia, and Minhang Water Company) (see Figure 1). There are six types of tables (including valves, flow points, fire hydrants, important users, pipelines, and nodes), and three layers (nodes, pipelines and equipment layer) in the GIS system, each object has various attributes, and the data can be connected with the 
hydraulic model system. The GIS system mainly consists of three subsystems: desktop GIS (C/S structure), Web-GIS (B/S structure) and hand GIS (M/S structure). At present, each subsystem has passed the trial operation stage, formally put into production. The operation process is stable and reliable, easy to use, and can fulfill the demands of browsing, querying, statistics and analysis of pipe network.

\section{SCADA SYSTEM FOR WATER DISTRIBUTION SYSTEM}

Shanghai Municipal Water Supply Controlling and Monitoring Center has built a perfect water supply SCADA system, that are able to monitor the whole process of from raw water gathering, delivering, water making and water distribution. Real-time monitoring is now covering all water plants, pump stations, reservoirs, pipe networks in central area, and the coverage is now extending towards county water plants and pump stations. The dispatching and monitoring department, as the front-line department for ensuring water supply safety, is fully functioning its role as "service, coordination, guidance, supervision and emergency response" in both daily coordination and the proceeding and implementation of major projects, it is responsible for the planning of the city's water supply scheduling, the real-time monitoring of operating pressure and status of each water plant, pump station and distribution network. Additionally, the department is responsible for the handling of all sorts of emergencies, and ensuring the city's water supply services via methods, including adjusting the boundary valves if necessary, and fully utilizing the ability of the integral scheduling of the city's water supply network. At present, the number of the distribution network online monitoring points is over 500 , for monitoring water flow, pressure, water quality and other information. The dispatching and monitoring department independently developed the Web application and scheduling operation and management system, and is able to share information with other departments such as Hydrological Administration, Meteorological Administration, Taihu Basin and Water Authority. The informationization not only provides a strong technical support for scientific scheduling and security of water supply, but also plays a crucial role in "resisting saline water intrusion, ensuring water supply services", "water supply in peak hours" and emergency responses.

\section{HYDRAULIC MODEL OF DISTRIBUTION NETWORK}

InfoWorksWS software was used to create the hydraulic model for DN700 in central area of Shanghai. In order to ensure the connectivity of the entire water distribution network, some of DN500 and DN300 pipelines were included in the model. The number of nodes in the entire network is more than $6.4 \times 10^{4}$ and the length of pipelines larger than DN700 is $2560 \mathrm{~km}$, which becomes the largest water distribution network model in China. Simulation results based on the calibration data (June 20, 2010 SCADA data) are in accord with the real data that can meet the model requirements for application. The model is mainly used for the simulation of the water transfer between the four water companies during peak hour and also for the development of the water supply protection scheme for switching source of Qingcaosha Reservoir.

\section{CONSTRUCTION AND PERSPECTIVE OF DIGITAL WATER QUALITY INFORMATION PLATFORM}

During "the Eleventh Five-Year" period, Shanghai Municipal Water Supply Controlling and Monitoring Center undertook the research project "Research on Technologies of Ensuring Water Quality in Urban Water Distribution Networks", which is included in the national water project "Safe transmission and Distribution Technology and Demonstration". According to the project assessment requirements, a central area digital water quality information platform was established (see Figure 2). The digital water quality information platform includes digital monitoring, digital evaluation and digital control. The main contents for displaying are: real-time monitoring data (residual chlorine, turbidity) and trend prediction, trend and evaluation system of chemical and biological stability indicators, pipe network hydraulic model, water quality model and water quality control technologies.

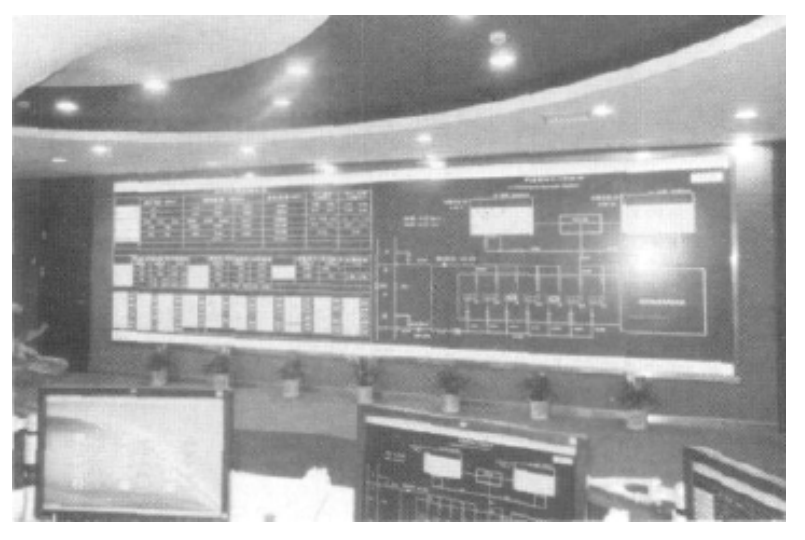

FIGURE II. DIGITAL WATER QUALITY INFORMATION PLATFORM OF CENTRAL AREA OF SHANGHAI

At present, the informatization construction of water supply network in Shanghai central area has begun to take shape, and is playing an important role in production and management. However, there are still some shortcomings, such as real-time information sharing and system integration. It still needs to fully utilize available resources to improve the informatization of the pipe network, and make it to a higher level.

The timely maintenance of each system is the focus of the work, the data synchronization update between GIS and pipe network model, charging system and pipe network model, SCADA system and pipe network model is essential. As the integrated water supply in Shanghai has developed rapidly, the water distribution network has been extended to the suburbs, water consumption varied over time and space, and the pipe network topology and node flow are constantly updated. The constantly updated pipe network topology, properties and other GIS data needs to enter the pipe network model through the interface update of GIS and pipe network model. Similarly, constantly updated water demand at node needs to enter the model by the interface update of charging system and pipe network model, SCADA data also needs to be timely updated into the model system. The operating conditions of water distribution network continue to change, so only the timely 
maintenance and update of pipe network model can maintain its effectiveness and be real-time.

Further application of the pipe network hydraulic model of central area mainly includes the following aspects:

1) Plan simulations for major changes in pipe network operating conditions (such as preplan simulation for saline water intrusion and preplan simulation for switching source of Qingcaosha reservoir). Make preplans for the water supply security protection to ensure water supply during emergencies. Changes in water flow direction and flow rate in water distribution network under abnormal conditions (such as the old water plant no longer in service, combined operation of pipe network in new water plants) can be obtained through the calculation of water distribution network model. The biofilm and fouling substances formed on the pipe wall will be washed into the bulk water due to these changes, which will adversely affected water quality, cause "yellow water" and other issues. Those pipes where changes occur can be identified through the simulation, so the protection plan could be made in advance. Also, pipes with a sharp increase in pressure can be detected through the simulation, thus the protection plan could be made in advance to reduce the risk of burst.

2) Simulation of the plan for water transferring within one network among all water companies. For example, during the earlier period of 2010 Expo while City South Water Company was building the advanced water treatment system, water of this area was supplied by Pudong Veolia; Pudong and Puxi achieved a joint scheduling scheme of water supply during the Expo period; and during the later period of the Expo, Pudong was supplied by City South Company through the South Yang pipe to compensate for the water demand as Yangsi water plant was no longer in service. Meanwhile, Pudong was supplied by City North, and City North and City South mutually support each other through connecting pipelines, the City South and Minhang did the same as well. The water demand in these plans needs to be calculated through the model. Due to the limitations of the original pipe network layout (larger pipelines for north-south direction, smaller for east-west direction), several large water companies cannot reach full water supply capacity in their own area. Additionally, the central distribution network cannot be changed significantly due to lack of excavation conditions. Therefore, water transfering within one network through the connected pipelines is able to overcome such constrains to some extent, so one network scheme is becoming more and more important.

3) Simulation of the pre-plan for ensuring water supply in west central area during summer peak periods. The western area, including Hongqiao, Xu Jing, eastern Qingpu district and Jiading Jiangqiao area, is located at the terminal of the water distribution network, and is far away from the water plants. According to the overall layout of urban planning, this region has become the development hot spot with relatively high demand for water. At present, low-pressure service areas exist due to the limitations brought by the location of water plants and the layout of the distribution network. The simulation of hydraulic model is used as the guidance for adjusting the structure of water supply before the construction of Taihe and
Xujing water plants, to ensure water supply during peak hours in this region.

At present, water quality model of the pipe network is still relatively new to water companies. There are mainly two kinds of models: macro-water quality model and micro-water quality model. Macro-water quality model is mainly used for simulations of water quality indicators with unclear microkinetics, such as water turbidity, $\mathrm{pH}$, etc. The model is built according to the historical data from water quality monitoring points set in the distribution network, so its outputs can only be the prediction results of water quality, and cannot be used to understand the overall operating conditions of the distribution network [1]. The micro- water quality model is used for simulation of water quality index with specific kinetic equations (such as the first order and second order residual chlorine decay model). The micro-water quality model is an extension of the micro-hydraulic model which requires high precision [2], and it has only been applied to small areas, such as the residual chlorine decay model and water age model in the Expo Park, for terminal water disinfection security and retained water cleaning. While central water companies focus on developing hydraulic models, some of them can start developing micro-water quality model. First, conduct regular measurements for the reaction coefficient $(\mathrm{kb})$ of outlet water. $\mathrm{kb}$ of mixed water supply area can be set by weight according to the water flow of different plants. In addition to the limited online water quality monitoring points, set up some artificial sampling points for detecting the residual chlorine (or total chlorine) every 15 min for $24 \mathrm{~h}$. Given data collected from both monitoring points and artificial sampling points, adjustment of the value of wall reaction coefficient $\mathrm{kw}$ is needed to make simulation results in accordance actual results.

The applications of water quality model after calibration are:

1) Simulation of chlorination scheme in water plants. If the concentration of residual chlorine at the terminal of the distribution network does not meet the requirements, one solution is to increase the initial concentration of chlorine in different water plants. Simulation could help find out the water plant from where chorine reaching the area with insufficient residual chlorine in the shortest time and the initial concentration of chlorine that can satisfy the requirements.

2) Simulation of booster chlorination scheme in water distribution network. If the residual chlorine concentrations at the terminal distribution sites do not meet the requirements, try booster chlorination at nodes (secondary pumping station, cell pumping station, etc.). Of course, it needs to figure out whether it is feasible for chlorination booster at those nodes. Simulation is used to find out feasible nodes which are the fastest options to fulfill the water quality requirement of areas with insufficient residual chlorination.

3) Simulation of partition scheme for the distribution network. The implementation of regionalized water supply is an important way to reduce power consumption and water leakage, and improve water quality and economic benefits, which has been verified by the practices in foreign cities [3]. The best partition plan with the youngest average water age among all nodes in this region, while satisfying demand of the 
water supply and pressure could be figured out through the simulation of different partition schemes.

4) Aging pipes are replaced with priority. The replacement of the aging pipeline cannot be done in one step, but needs to be carried out in a scientific and orderly manner. According to the water quality monitoring data, the water quality parameters are optimized by the corrector, and the wall attenuation coefficient is introduced in the properties of aging pipelines to be reconstructed. The pipeline with a larger wall attenuation coefficient has the priority to be replaced.

5) Safety assessment of water source switching. Under the premise of satisfying the water demand and pressure, the influence of water source switching on the water quality in the distribution network can be evaluated by simulations of water age and of region with enough residual chlorine. A safe and feasible water source switching scheme can be found by comparing different schemes.

6) Cleaning of the retained water at the terminal of pipelines. Reasonable pipeline cleaning intensity and feasible pipeline cleaning plan could be figured out through simulation of the dynamic effects of different cleaning intensity on the age of retained water at the terminal of pipelines.

The next step is to integrate various types of operating data, pipeline pressure, and water flow and water quality monitoring data to achieve real-time monitoring of the entire distribution system. In addition, combine the GIS, SCADA system, charging system, customer service, hydraulic model and water quality model together, and use different kinds of tools for simulation, analysis and prediction of the distribution network, strengthen information management and control of operation, and enable web browsing.

\section{CONCLUSIONS}

1) The information system of water distribution network in central area of Shanghai has been initially completed and achieved some successes. The development and application of the water quality model needs to be strengthened, and system maintenance, update and integration will be the future emphasis.

2) The emergency scheduling with one network and zone management are not conflicted as one network scheduling is for ensuring water supply during emergency and peak hours. However, from the management prospective, dividing water distribution network into zones is more beneficial to pressure management, water quality management and leakage management.

\section{ACKNOWLEDGMENT}

Part of this work was supported by National Water Special Project of China (2009ZX07421-005, 2012ZX07403-002) and Key projects of Shanghai science and Technology Commission (16DZ1201200, 17DZ1202704).

\section{REFERENCES}

[1] Zhao, H. B., Li, X., Zhao, M. Water Supply Network Hygiene (in Chinese), Beijing: China Building Industry Press, 2008.
[2] Shu, S. H., Zhao, M., Gao, J. L., He, W. J., Yuan, Y. X. (2010). Problems of water quality model calibration in distribution system and the countermeasures (in Chinese). Journal of Harbin Institute of Technology, 41(10), 74-77.

[3] Shu, S. H., Zhao, H. B. (2008). Challenges and Opportunities to Water Distribution Network Modelling in China (in Chinese). China Water and Wastewater, 24(8), 5-7. 